\title{
The Qualities of Leadership: Direction, Communication, and Obfuscation
}

\author{
Torun Dewan
}

Department of Government, London School of Economics

t.dewan@lse.ac.uk

\author{
David P. Myatt
}

Department of Economics, University of Oxford

david.myatt@economics.ox.ac.uk 


\begin{abstract}
Party activists wish to (i) advocate the best policy and yet (ii) unify behind a common party line. An activist's understanding of his environment is based on the speeches of party leaders. A leader's influence, measured by the weight placed on her speech, increases with her judgement on policy (sense of direction) and her ability to convey ideas (clarity of communication). A leader with perfect clarity of communication enjoys greater influence than one with a perfect sense of direction. Activists can choose how much attention to pay to leaders. A necessary condition for a leader to monopolize the agenda is that she is the most coherent communicator. Sometimes leaders attract more attention by obfuscating their messages. A concern for party unity mitigates this incentive; when activists emphasize following the party line, they learn more about their environment.
\end{abstract}

(C) The authors. All rights reserved. Short sections of text, not to exceed two paragraphs, may be quoted without explicit permission provided that full credit, including $($ cotice, is given to the source 
Political scientists and commentators agree that good leadership is important, indeed fundamental, to the successful performance of organizations. But what is leadership? When is leadership good? When is it successful? Which qualities contribute to good and successful leadership, and in what measure do they contribute?

Leadership can be important when political actors wish to act in tune with both their environment and with each other. An individual may be unsure about the general circumstances surrounding his decision and uncertain about others' likely actions. Leaders can help. As Levi (2006) argued recently, "leadership ... provides the learning environment that enables individuals to transform or revise beliefs." By fostering an understanding of the political landscape a leader helps to inform the actions of a mass and, through her communication, unifies expectations about how others will act.

To illustrate, consider a political party populated by a mass of party activists. An activist advocates the policy he believes to be desirable, based on his understanding of the political environment. He may, however, not know which policy is best; leadership can help him in his quest. As a member of a political organization, he is also concerned with the internal cohesion of his party. A party is more successful when activists advocate similar policies, and less so when there is discordance amongst the broader membership. Because of this a party activist would like to advocate a policy that is in line with others; in the absence of leadership the "party line" may be hard to discern.

In this situation a leader has influence via her communication. She might convey information to activists, thus aiding them in their advocacy; for example, a leader's speech might be observed by the party membership. This also has focal properties: her speech could yield a common viewpoint around which support can coalesce. This is important, since an activist faces uncertainty not only about which is the best policy, but also about what others think is the best policy. Successful coordination depends upon accurate assessments of others' beliefs; leadership helps provide such assessments.

Within this framework, good leadership helps activists to achieve their goals: the speech of a good leader generates the understanding that is needed for activists to advocate the right policy, and to advocate it together. On the other hand, a successful leader is one who has influence: her speech impacts upon the actions taken by activists. The performance of a leader on both dimensions depends on her qualities. As Levi (2006) suggested, "[the] quality of government depends on the quality of institutions and constitutional design but also on the quality of leadership, and the accuracy of beliefs held by the population about the state of the world in which they live..." But which qualities are relevant? 
The first quality that we consider is a leader's sense of direction. When a leader speaks she conveys her private information about the best policy for the party. The accuracy of that information (its correspondence to the truth) reflects her judgement. History provides us examples of those who, on the bigger issues of the day, appear to have an instinct of the best course to pursue. Of George Washington, for example, Ellis (2005) wrote "whatever minor missteps he had made along the way, his judgement on all the major political and military questions had invariably proved prescient, as if he had known where history was headed ... his genius was his judgement." Such a sense of direction might not only focus on the best course of action, but also on the action that is most compatible with the wider mass of political actors. For example, Carwardine (2003) argued that "to fathom the thinking of ordinary citizens and to reach out to them with uncommon assurance" was a central achievement of Abraham Lincoln.

The second quality that we consider is a leader's clarity of communication. Being able to identify perfectly the best policy is of little use unless a leader can accurately communicate her message to the wider mass of activists. Increased clarity therefore enhances the informativeness of a leader's speech. However, there is a second effect. An activist asks not only what is the content of the message received from a leader, but how will others interpret the message. A clear message is better able to act as a focal point. Indeed, a speech which points all activists in the wrong direction, but is commonly interpreted, may sometimes be preferable to one which points in the right direction but lacks a common interpretation. To identify a leader with the gift of clear communication we might consider Andrew Jackson about whom Brand (2005) wrote "... his diction was clear and his purpose unmistakable. No one ever listened to a speech or a talk from Andrew Jackson who, when he was done, had the least doubt as to what he was driving at."

Consider a politician who arguably embodied both of our leadership qualities. As a backbencher from 1936 to 1940, Winston Churchill advocated preparation for war, whilst successive Prime Ministers, first Baldwin and then Chamberlain, vacillated in the light of uncertainty over the extent of Germany's military ambitions. On this issue, the historical record suggests that Churchill had a sharper sense of direction than his rivals: he identified the threat facing the allies, and, moreover, a military strategy to deal with it. A further Churchillian skill was communication; his speeches serving both to motivate and create a common understanding of the perils faced by Britain and her allies.

Rarely, however, does an individual embody both characteristics, and in such abundance, that she trumps all rivals. More usually different leaders (or potential leaders) vary across these dimensions. A contemporary example involves the British Prime Minister, Tony Blair, and his (at the time of writing) heir apparent, Gordon Brown. Both are able leaders. 
However, whilst Chancellor Brown is widely perceived as amongst the most intellectually astute of his cohort, he is sometimes perceived as a poor communicator. By contrast, although Prime Minister Blair's judgement has been called into question, not least over his handling of the second Iraq war, he is widely perceived as one of the best communicators in the business. Blair's strength lies in the articulation of a coherent central message.

When there is only one leader, and activists have no other sources of information, then their optimal actions are clear: they can do no better than follow the advice given in the leader's speech. However, when there is no clear leader apparent, individuals must assess different leaders according to their competencies. In our formal model, we find a unique equilibrium in which the policy advocated by a party activist is based on a weighted average of the speeches he hears. The weight placed on a speech acts as an index of the orator's effectiveness; other things equal, it can measure the success of a leader. Summing the indices across the set of leaders yields a welfare measure for the party. Hence anything that increases the effectiveness of a leader also increases party performance. So long as leaders' qualities are exogenous, good and successful leadership coincide.

Unsurprisingly, a leader's influence is increasing in both her sense of direction and her clarity of communication. Importantly, however, clarity of communication has a relatively larger effect. For example, a leader who can perfectly communicate an imperfect opinion has more influence than a leader who imperfectly communicates a perfect one. The effect is most stark when party activists feel a great need for party unity: when a leader communicates clearly, activists develop a common understanding of the party line even though that party line may differ from the ideal policy.

Of course, the qualities of leadership may not be exogenous. Take, for instance, the clarity of a leader's communication. Whereas her sense of direction may be determined by her natural ability, the clarity of her message is affected by whether activists listen to her: if activists pay careful attention to her speeches then they understand what she has to say. But activists must choose who to listen to. Paying attention to one leader entails being less attentive to another. In our formal analysis we extend our model to a world in which activists endogenously decide who to listen to. In the unique equilibrium of this game, the attention paid to leaders depends upon their personal leadership qualities.

Given time constraints, activists might devote all of their attention to the speech of a single leader. Since such a leader receives unreserved attention she has undiluted influence; the leader is a de facto dictator. But which leader might command such an audience? We find that a necessary condition is that she speaks with greater clarity than all others. Correspondingly, when the conditions for de facto dictatorship are not satisfied, then, ordering 
their leaders in terms of clarity, activists listen only to the elite subset with the best communication abilities, paying no attention to the rest. The size of this elite depends upon activists' relative preference for policy versus party unity. When the coordination motive dominates then the clearest orator provides an irresistible focal point for the party.

Our initial results highlight the importance of the clarity of a leader's communication. This might lead one to suspect that attention-seeking leaders communicate as clearly as possible. This hunch is mistaken. Although sufficient clarity is needed for activists to pay some attention, it does not follow that they pay most attention to the leader with the greatest clarity of communication. In fact, we find circumstances in which a relatively poor communicator enjoys the lion's share of the party's attention.

To understand why this is so, note that a good communicator is able to deliver the essence of her message in a short period of time. An activist need not linger amongst her audience; keen to further his understanding of his environment, and having heard what he needs to hear, he quickly moves on to listen to other leaders.

With this in mind, a leader may adapt her rhetorical strategy to increase the attention paid to her. In a further extension to our formal model, we allow leaders to choose the clarity of their speeches. We assume that leaders are attention-seeking: each leader would like to maximize the proportion of time that party activists spend listening to her. If at all possible, a leader would like to monopolize the agenda so that party members listen to no other leader. This formulation drives a wedge between the notions of good leadership and successful leadership: here, a good leader helps party members to advocate the right policies, whereas a successful leader enjoys the biggest audience.

We find a unique equilibrium of this attention-seeking game. An important lesson is that a leader purposefully obfuscates her message; after all, if she spoke with perfect clarity then activists would need to listen to her for only the briefest of moments. On the other hand, she does not completely obscure her message since she must say something of relevance if she is to attract an audience. Obfuscation hampers the ability of activists to learn; thus successful leadership need not be good leadership.

The attention-maximizing level of clarity chosen by a leader is increasing in her sense of direction: she speaks more clearly if she has more to say. Of course, her chosen clarity also depends on the qualities of others. Competitive tensions between leaders arise between leaders endowed with different senses of direction. Despite these differences, we find a unique equilibrium in which all leaders choose to speak with the same clarity. Thus, whilst a necessary condition for membership of a leadership elite is sufficient clarity, the relative influence of a member of such an elite is determined solely by her sense 
of direction. Moreover, the equilibrium clarity of communication chosen by all leaders in the elite increases with each individual leader's sense of direction. Thus improving a leader's judgement has two effects: it directly increases the quality of her leadership; and it encourages all leaders to speak more clearly, so further enhancing party performance.

The willingness of a leader to blur her message also depends critically on the importance of party unity. When unity is important, activists are most concerned with developing an understanding of the actions of their fellow party members; they emphasize adoption of the party line. In pursuit of that goal activists pay more attention to clearer speakers and, reacting to this incentive, leaders communicate more clearly. The final twist to our story is that parties which focus on party unity, thus ensuring that all activists are singing from the same hymn sheet, also develop a better understanding of policy. The lesson is that parties which emphasize unity provide the correct incentives for good leadership.

Our paper proceeds as follows. Following a brief discussion of some related literature, we describe the policy advocacy game played by activists and the information they receive via the speeches of leaders. We characterize the influence of the leaders and explore comparative-static results (Propositions 1-2). Extending our model, we allow activists to choose the leaders to whom they listen, and find conditions under which an elite subset of leaders controls the agenda (Propositions 3-4). Finally, we allow leaders to engage in obfuscation, and calculate the welfare implications for the party (Propositions 5-6).

\section{RELATED LiTERATURE}

In our model, leaders help activists to act in concert with their fellow partisans. This focal role of leadership was suggested by Calvert (1995) and Myerson (2004). Dewan and Myatt (2006) developed these insights in a model in which activists must coordinate on one of two policies, the relative strengths of which are uncertain. They derived conditions under which a democratic party conference would follow the advice of a single leader. In contrast to our model, their (single) leader communicates with perfect clarity. Here we allow for multiple attention-seeking leaders and the endogenous choice of clarity.

The game played by activists is strategically equivalent to the Keynesian "beauty context" described by Morris and Shin (2002). In the Morris-Shin world, agents learn via two information sources: an imperfect public signal which is commonly observed and interpreted; and private signals which are independently and identically distributed amongst agents. ${ }^{2}$ Interpreted in our framework their public signal is a leader with perfect clarity

\footnotetext{
${ }^{2}$ Morris and Shin (2002) demonstrated that agents pay relatively more attention (more than is socially desirable from an information-aggregation perspective) to their public signals. For extensions and critical analysis in economic contexts see Angeletos and Pavan $(2004,2006)$.
} 
of communication but an imperfect sense of direction. Conversely, their private signal is a leader with a perfect sense of direction but imperfect clarity of communication. We analyze leaders with an arbitrary mix of these different attributes, and so the Morris-Shin game is a special case of ours. Moreover, by personalizing signals, in the form of leaders, we are able to explore the issue of endogenous clarity of communication. ${ }^{3}$

Our leaders influence their followers' beliefs. Hermalin (1998) considered a similar issue: as in Holmström (1982), a team's output is related to (costly) individual actions and an unknown productivity factor. Team members face a classic collective-action problem, and fail to internalize the group benefits of effort. Hermalin (1998) developed the idea of leading by example. A leader has better information about productivity and chooses her effort publicly. This serves as a credible signal which encourages team members. In our paper leaders' speeches are signals in the statistical sense rather than the game-theoretic sense; the only strategic move of a leader is to change the precision of information that she transmits. Moreover, there is no conflict in the underlying preferences of activists; they would all back the ideal policy if only they could share all of their information.

The actors in our world agree about policy, and a leader does not mislead activists about the world as she sees it. The focus, then, is on the obfuscation that emerges from rhetorical strategies. This relates our work to that of Riker (1996). He focused on the issues party leaders emphasize. He argued, under his dominance principle, that if a party dominates in terms of its rhetorical appeal on an issue then the other abandons all appeals on that issue. This idea has also been the subject of empirical work (Sigelman and Buell, 2004).

In our model the only constraints to perfect revelation of a leader's signal are her natural ability to convey accurately her information and her strategic desire to obfuscate. This focus on the (endogenous) clarity in leaders' communication is related to the study of strategic ambiguity on policy (Zeckhauser, 1969; Shepsle, 1970, 1972a,b; Page, 1996; Kroszner and Stratmann, 2005). That literature focused on a scenario where politicians are equivocal in order to appeal to a broader section of voters. Zeckhauser (1969) found that an ambiguous strategy does better than one which is clear in its commitment to a specific policy; Shepsle (1970) showed that an ambiguous strategy beats one which is constrained to be less ambiguous, acknowledging the "politician's advantage in speaking half-truths and in varying his appeals with variations in audience and political climate." ${ }^{4}$

\footnotetext{
${ }^{3}$ Edmond (2005) and Angeletos, Hellwig, and Pavan (2006) considered endogenous information transmission when a large mass must coordinate in order to overthrow a regime. Angeletos, Hellwig, and Pavan (2006) analyzed a dynamic setting in which costly defensive actions influence beliefs about a regime's vulnerability. In Edmond (2005), agents receive private signals about the regime's vulnerability but, since the regime influences the release of information via signal jamming, agents are susceptible to its propaganda. ${ }^{4}$ Two recent papers built upon these insights whilst analyzing the endogenous choice of policy clarity. Aragonés and Neeman (2000) studied a scenario where the best post-election policy is initially unknown.
} 
Conceptually, equivocation and obfuscation, whilst related to the clarity of political communication, are different rhetorical strategies. Indeed our focus on the latter relates our work more closely to the "cheap talk literature" developed initially by Crawford and Sobel (1982) in economics and extended to political settings by Gilligan and Krehbiel (1987), Li, Rosen, and Suen (2001), and Persico (2004), amongst others. In cheap-talk scenarios an informed politician can never credibly reveal her signal of the true state of the world, and is restricted to sending garbled messages due to a commonly understood policy bias on her part. Here leaders have no inherent policy bias. A leader could credibly reveal her signal of the true state of the world if she so wished. The incentive to obfuscate arises nevertheless, through a process of competition between attention-seeking leaders. ${ }^{5}$

Office seekers also wish to implement the best policy. Remaining vague maximizes benefits once in office, but affects the probability of being elected. Mierowitz (2005) considers politicians who learn about voters' preferences during a campaign which involves both primary and general elections. Candidates who refrain from committing to specific policies have greater flexibility upon receiving information from the primary. ${ }^{5}$ Other approaches to leadership include that of Fiorina and Shepsle (1989), who analyzed leaders as agents of a party, and Bueno de Mesquita, Morrow, Siverson, and Smith (2002; 2003), who asked how the survival strategies of leaders and are influenced by the institutional environment they inhabit. 
Our study of the role and qualities of leadership builds upon a simple game in which party activists wish to coordinate their actions in an uncertain environment.

The players are a unit mass of party activist indexed by $t \in[0,1]$. A player advocates a policy $a_{t} \in \mathbb{R}$. This might be interpreted as the policy he advocates at a party conference, or the policy he promotes during an election campaign. Drawing together the actions of all party members, the "party line" is the average policy advocated: $\bar{a}=\int_{0}^{1} a_{t} d t$.

A party activist pursues two objectives. Firstly, he would like to advocate the policy $\theta$ that best meets the party's needs. Secondly, an activist wishes to coordinate with others in his party. That is, a concern for party unity drives him to follow the party line. We can represent these twin concerns via a pair of quadratic loss functions:

$$
u_{t}=\bar{u}-\underbrace{\pi\left(a_{t}-\theta\right)^{2}}_{\text {(i) concern for policy }}-\underbrace{(1-\pi)\left(a_{t}-\bar{a}\right)^{2}}_{\text {(ii) desire for party unity }} .
$$

Here $\pi$ indexes an activist's relative concern for choosing the ideal policy compared to maintaining party unity. When $\pi=1$ an activist is solely concerned with advocating the best policy; when $\pi=0$, by contrast, he cares only about the perception of party unity and seeks only to minimize the distance between himself and the party line.

When activists share common knowledge of $\theta$ then it is optimal for them all to advocate the same ideal policy $a_{t}=\theta$. In fact, this is the unique Nash equilibrium of the game. When this is so there is no tension between the activists' twin objectives.

However, when $\theta$ is unknown an activist is unsure of the best policy. He may also be unsure of the likely actions of others. Given this uncertainty, he maximizes his expected payoff $\mathrm{E}\left[u_{t}\right]$, where the expectation is taken with respect to his beliefs about the ideal policy and the party line. The minimization of $\pi \mathrm{E}\left[\left(a_{t}-\theta\right)^{2}\right]+(1-\pi) \mathrm{E}\left[\left(a_{t}-\bar{a}\right)^{2}\right]$ leads directly to a simple first-order condition and optimal advocacy choice

$$
a_{t}=\pi \mathrm{E}[\theta]+(1-\pi) \mathrm{E}[\bar{a}]
$$

which is a weighted average of the expected ideal policy, from the perspective of the activist, and his understanding of the average policy advocated by the party at large.

An activist's expectations are formed based on any information available to him. Specifically, each activist observes $n$ informative signals which form a collection $\tilde{s}_{t} \in \mathbb{R}^{n}$ capturing all information relevant to his play of the game. An advocacy strategy is then a mapping from signal realizations to policy choices; formally, $a_{t}=A\left(\tilde{s}_{t}\right): \mathbb{R}^{n} \rightarrow \mathbb{R}$. 
An advocacy strategy yields a (strict) Bayesian Nash equilibrium when it specifies an optimal choice for each activist, given his beliefs, and when those beliefs are consistent with the party-wide use of the strategy. ${ }^{6}$ Given activists use a strategy $A(\cdot)$, an activist's expectation of the party line is $\mathrm{E}\left[\bar{a} \mid \tilde{s}_{t}\right]=\mathrm{E}\left[A\left(\tilde{s}_{t^{\prime}}\right) \mid \tilde{s}_{t}\right]$ for $t^{\prime} \neq t .^{7}$ Similarly, his expectation of the ideal policy is $\mathrm{E}\left[\theta \mid \tilde{s}_{t}\right]$. Hence the strategy $A(\cdot)$ forms an equilibrium if and only if

$$
A\left(\tilde{s}_{t}\right)=\pi \mathrm{E}\left[\theta \mid \tilde{s}_{t}\right]+(1-\pi) \mathrm{E}\left[A\left(\tilde{s}_{t^{\prime}}\right) \mid \tilde{s}_{t}\right] .
$$

Thus an activist's strategy is a weighted average of the expected ideal policy and his understanding of the average policy advocated by the party at large.

To find an equilibrium we need only solve Equation $(\star)$ to find the equilibrium advocacy strategy $A(\cdot)$. However, we need to specify how signals help an activist to form beliefs about the ideal policy $\theta$ and beliefs about the signals seen by other activists. To do this, we turn to specify the mechanism via which activists learn.

\section{THE ROLE OF LEADERSHIP}

Leaders can help an activist to develop his beliefs about policy and the likely actions of others. Activists begin with no knowledge of $\theta$. To inform them we employ $n$ party leaders indexed by $i \in\{1, \ldots, n\}$. In our initial specification, the term "leader" can be viewed as a mere label for an informative signal. Nevertheless, this personification of the information source is useful when we subsequently introduce a role for strategic leaders who may wish to manipulate the information activists obtain.

Each leader forms an independent, unbiased, and private opinion of the ideal policy for the party. Formally, leader $i$ observes an informative signal $s_{i}$ satisfying

$$
s_{i} \mid \theta \sim N\left(\theta, \kappa_{i}^{2}\right) \text { and so } \frac{1}{\kappa_{i}^{2}}=\text { Sense of Direction, }
$$

where leaders' signals are statistically independent. The variance $\kappa_{i}^{2}$ captures an important skill: a leader's ability to judge the correct state of the world. When $\kappa_{i}^{2}$ is small she is better able to assess policy, and so the precision $1 / \kappa_{i}^{2}$ indexes her sense of direction.

\footnotetext{
${ }^{6}$ It is without loss of generality to restrict attention to symmetric strategy profiles in which all activists use the same strategy $A(\cdot)$. Since each individual activist is negligible then, conditional on the information available, a best reply for activist $t$ is also a best reply for activist $t^{\prime} \neq t$; the labels of players do not matter. Moreover, since a player's payoff is a strictly concave function of his action, his best reply must be unique. Thus any Bayesian Nash equilibrium is symmetric and involves the play of strict best replies.

${ }^{7}$ Activist $t$ 's own action has a negligible effect on the party-wide average. His expectation of $\bar{a}$ satisfies
}

$$
\mathrm{E}\left[\bar{a} \mid \tilde{s}_{t}\right]=\mathrm{E}\left[\int_{0}^{1} a_{t^{\prime}} d t^{\prime} \mid \tilde{s}_{t}\right]=\int_{0}^{1} \mathrm{E}\left[a_{t^{\prime}} \mid \tilde{s}_{t}\right] d t^{\prime}=\int_{0}^{1} \mathrm{E}\left[A\left(\tilde{s}_{t^{\prime}}\right) \mid \tilde{s}_{t}\right] d t^{\prime}=\mathrm{E}\left[A\left(\tilde{s}_{t^{\prime}}\right) \mid \tilde{s}_{t}\right]
$$


Our leaders address the mass of activists. A leader's speech conveys information about her opinion. We assume that her preferences over policy choices match those of party members. Hence she has no strategic incentive to misrepresent her views and describes the world as she sees it. Alas, she is unable to communicate her views perfectly: each activist $t$ observes the leader's private signal plus noise. Formally,

$$
\tilde{s}_{i t} \mid s_{i} \sim N\left(s_{i}, \sigma_{i}^{2}\right) \text { and so } \frac{1}{\sigma_{i}^{2}}=\text { Clarity of Communication }
$$

Conditional on $s_{i}$, the final signals received by different activists (that is, how they interpret a speech) are statistically independent. The variance $\sigma_{i}^{2}$ reflects a second important skill: a leader's ability to communicate clearly. The precision $1 / \sigma_{i}^{2}$ indexes her ability to express her privately held opinions in a public forum. Unless her clarity of communication is perfect, activists do not necessarily hear what the leader is trying to say. Furthermore, activists obtain different impressions of the leader's views.

\section{Choosing Who To Follow}

We now ask how activists react to the speeches they hear. This reaction is captured by an equilibrium policy advocacy strategy $A\left(\tilde{s}_{t}\right)$ satisfying Equation $(\star)$.

Attention focuses on a simple, robust, and easily interpreted class of strategies: an activist employs a linear strategy if he advocates a weighted average of the speeches he hears, so that $A\left(\tilde{s}_{t}\right)=\sum_{i=1}^{n} w_{i} \tilde{s}_{i t}$ where $\sum_{i=1}^{n} w_{i}=1$. The weight placed on a speech measures a leader's influence. Happily, Proposition 1 confirms that the unique equilibrium involves a linear strategy. This stems from the use of the normal distribution: normality ensures that the conditional expectations of the ideal policy $\mathrm{E}\left[\theta \mid \tilde{s}_{t}\right]$ and of another activist's signal $\mathrm{E}\left[\tilde{s}_{t^{\prime}} \mid \tilde{s}_{t}\right]$ are both linear in $\tilde{s}_{t}$. Given that this is so, when others use a linear strategy, an activist finds that his best reply is to use a linear strategy in response. ${ }^{8}$

Focusing on linear strategies, the equilibrium weights maximize the aggregate welfare of the party. To verify this claim, consider a change in $a_{t}$. Whilst the direct effect on activist $t$ is fully incorporated into his calculations, the change imposes externalities on others. For instance, an increase in $a_{t}$ pushes up the party line $\bar{a}$. Activist $t^{\prime} \neq t$ enjoys a positive spillover if $a_{t^{\prime}}>\bar{a}$ (his action is now closer to the party line) but suffers if $a_{t^{\prime}}<\bar{a}$. These externalities conveniently sum to zero. By definition, the party line $\bar{a}$ is the average policy advocated across the party and so, in expectation, the policies advocated by individual

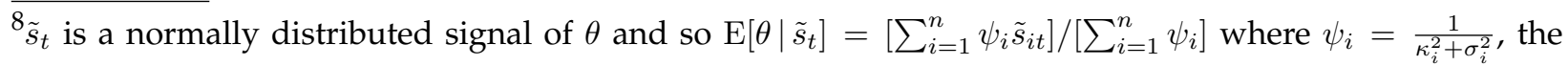
quality-of-information term used in Proposition 2. If others use a linear strategy then $\mathrm{E}\left[A\left(\tilde{s}_{t^{\prime}}\right) \mid \tilde{s}_{t}\right]=$ $\sum_{i=1}^{n} w_{i} \mathrm{E}\left[\tilde{s}_{i t^{\prime}} \mid \tilde{s}_{t}\right]$. The normal distribution ensures that each element $\mathrm{E}\left[\tilde{s}_{i t^{\prime}} \mid \tilde{s}_{t}\right]$ is linear in $\tilde{s}_{t}$. Drawing these observations together, the best response $a_{t}=\pi \mathrm{E}\left[\theta \mid \tilde{s}_{t}\right]+(1-\pi) \mathrm{E}\left[A\left(\tilde{s}_{t^{\prime}}\right) \mid \tilde{s}_{t}\right]$ is linear in $\tilde{s}_{t}$. Hence, if other activists use a linear advocacy strategy then activist $t$ will also find it optimal to use a linear strategy.
} 
party members lie symmetrically above and below $\bar{a}$. Since the various externalities from an activist's action cancel out, he must face socially correct incentives at the margin.

With our claim established, we now calculate the weights that maximize aggregate party welfare and hence find the unique equilibrium of our advocacy game. The party's welfare, which corresponds to the ex ante expected payoff of a randomly chosen activist, satisfies $\mathrm{E}\left[u_{t}\right]=\bar{u}-\pi \mathrm{E}\left[\left(a_{t}-\theta\right)^{2}\right]-(1-\pi) \mathrm{E}\left[\left(a_{t}-\bar{a}\right)^{2}\right]$. Taking the first quadratic loss term, $a_{t}$ is a weighted average of unbiased signals of $\theta$, and so $\mathrm{E}\left[\left(a_{t}-\theta\right)^{2}\right]=\operatorname{var}\left[a_{t} \mid \theta\right]$. Turning to the second quadratic loss term, $a_{t}$ is equal to $\bar{a}$ on average, and so $\mathrm{E}\left[\left(a_{t}-\bar{a}\right)^{2}\right]=\operatorname{var}\left[a_{t} \mid s\right]$, where $s$ is the vector of signals seen by the party leaders. Putting these elements together,

$$
\text { Party Welfare }=\bar{u}-\pi \underbrace{\sum_{i=1}^{n} w_{i}^{2}\left(\kappa_{i}^{2}+\sigma_{i}^{2}\right)}_{\text {(i) } \operatorname{var}\left[a_{t} \mid \theta\right]}-(1-\pi) \underbrace{\sum_{i=1}^{n} w_{i}^{2} \sigma_{i}^{2}}_{\text {(ii) var }\left[a_{t} \mid s\right]}=\bar{u}-\sum_{i=1}^{n} w_{i}^{2}\left[\pi \kappa_{i}^{2}+\sigma_{i}^{2}\right]
$$

Notice that any noise in the information sources available to activists detracts from party welfare. Interestingly, the noise $\pi \kappa_{i}^{2}+\sigma_{i}^{2}$ arising from a leader's speech does not equally weight her qualities. A lack of clarity in a leader's communication frustrates activists' coordination as well as lessening the information content of her speech. By contrast, a failing in her sense of direction, whilst affecting an activist's ability to advocate the ideal policy, has no impact on the party membership's coordination; it thus attracts a reduced weight of $\pi$. These observations regarding the different effects of our leadership skills are reflected in the equilibrium weights which maximize party welfare.

Proposition 1. There exists a strict Bayesian Nash equilibrium. This equilibrium is unique and symmetric: all activists use the same linear strategy $A\left(\tilde{s}_{t}\right)=\sum_{i=1}^{n} w_{i} \tilde{s}_{i t}$ with weights satisying

$$
w_{i}=\frac{\hat{\psi}_{i}}{\sum_{j=1}^{n} \hat{\psi}_{j}} \text { where } \hat{\psi}_{i}=\frac{1}{\pi \kappa_{i}^{2}+\sigma_{i}^{2}} .
$$

Party welfare (the expected payoff of a representative activist) is $\bar{u}-1 /\left[\sum_{i=1}^{n} \hat{\psi}_{i}\right]$. A leader's influence, indexed by $\hat{\psi}_{i}$, increases with both her sense of direction and her clarity of communication.

This result is intuitive: an influential leader clearly communicates her sharp sense of direction. The presence of $\pi$ in the influence index $\hat{\psi}_{i}$ ensures that a leader's ability to give clear expression to her views is relatively more important than her ability to understand the political environment. $\hat{\psi}_{i}$ measures influence and therefore successful leadership; however, since welfare increases with $\sum_{i=1}^{n} \hat{\psi}_{i}$ it also measures good leadership.

To obtain further insight recall once again that a leader helps activists to learn about policy and to coordinate. Her message about policy is muddled by two sources of noise: any errors of judgement on her part (the variance $\kappa_{i}^{2}$ ) plus any misunderstanding of what she 
says (the variance $\sigma_{i}^{2}$ ). Combining these sources of noise,

$$
\tilde{s}_{i t} \mid \theta \sim N\left(\theta, \kappa_{i}^{2}+\sigma_{i}^{2}\right) \quad \text { so that } \quad \psi_{i} \equiv \frac{1}{\kappa_{i}^{2}+\sigma_{i}^{2}}=\text { Quality of Information. }
$$

Hence if activists care only about discovering the best policy (so that $\pi=1$ ) then the two components of a leader's skill set are equally important. However, activists also care about coordination, and a leader's speech can act as a convenient focal point. For this to be true it is useful if different activists tend to hear the same thing.

An appropriate measure of the commonality of messages received is the correlation between what is heard by different activists. To calculate this, note that the covariance between two signals is $\operatorname{cov}\left[\tilde{s}_{i t}, \tilde{s}_{i t^{\prime}} \mid \theta\right]=\kappa_{i}^{2}$. This yields the correlation coefficient

$$
\rho_{i}=\frac{\kappa_{i}^{2}}{\kappa_{i}^{2}+\sigma_{i}^{2}}=\text { Correlation of Messages, }
$$

which depends on the relative strength of a leader's clarity of communication and sense of direction. When a leader becomes a perfect communicator $\left(\sigma_{i}^{2} \rightarrow 0\right)$ the correlation satisfies $\rho_{i} \rightarrow 1$ and everyone hears the same message; the leaders' speech becomes a public signal. On the other hand, when a leader becomes a perfect director $\left(\kappa_{i}^{2} \rightarrow 0\right)$ the correlation satisfies $\rho_{i} \rightarrow 0$; the messages received are independent private signals of $\theta$.

Proposition 2. In the unique Bayesian Nash equilibrium, a leader's influence satisfies

$$
\hat{\psi}_{i}=\frac{\psi_{i}}{\left(1-\rho_{i}\right)+\pi \rho_{i}},
$$

and hence her influence increases with the quality of information she offers to activists and the correlation of the messages that they hear. Comparing two leaders $i$ and $j$ satisfying $\rho_{i}>\rho_{j}$ (so that leader $i$ is a more coherent communicator) the influence of $i$ relative to $j$ grows as $\pi$ falls.

Since $\pi$ is the weight placed on any deviation from the ideal policy, the remainder $1-\pi$ is the desire for party unity. Proposition 2 reveals the determinants of good leadership:

$$
\text { Leadership }=\frac{\text { Quality of Information }}{1-[\text { Correlation of Messages } \times \text { Desire for Unity }]} .
$$

Fixing the quality of information provided, coherent communication determines the effectiveness of leadership, and more so when there is a greater desire for party unity. In fact, it is useful to compare a perfect communicator $\left(\rho_{i}=1\right.$, so that $\left.\hat{\psi}_{i}=\psi_{i} / \pi\right)$ with a perfect director $\left(\rho_{j}=0\right.$, so that $\left.\hat{\psi}_{j}=\psi_{j}\right)$. As $\pi$ falls to zero, so that only party unity matters, the perfect communicator becomes far more influential than the perfect director. 


\section{Choosing Who To Listen To}

We have studied a model in which activists received exogenous signals via the speeches of leaders. We might think of all party members attending a large party conference where each listens carefully to speeches made from the conference platform. An implicit assumption is that activists form a captive audience. Under this assumption, we concluded that the clearest communicators enjoy relatively more influence.

Of course, speeches convey information only if they are heard. Activists may abstain from listening to a particular speech, or may not devote their full attention to it. The clarity of a leader's message depends not only on the clarity of her communication but also on the willingness of others to listen; but the decision to listen is endogenous. This becomes important when gathering information, through listening to speeches, is costly. This is the case, for example, when activists have a limited attention span.

Given that activists choose who to listen to, leaders may try and capture their attention. How much attention a leader receives depends upon the skills with which she is endowed; specifically the clarity of her communication and her sense of direction. Whilst the latter might be seen as an exogenous trait, the former is more manipulable; a leader may vary her clarity as and when the need arises. That is, the overall clarity of a message depends endogenously on both speaker and audience.

To analyze these effects we extend our model. Activists are each endowed with a single unit of time (perhaps the duration of a party conference). They allocate their time to different leaders: activist $t$ spends a proportion $x_{i t}$ of his time listening to what leader $i$ has to say. We think of him as observing a sample of (noisy) observations of the leader's views. In this sense, the time spent listening represents the sample size. In the usual way, the sample variance declines with the sample size; equivalently, the precision of the aggregate signal is linearly increasing in $x_{i t}$. This leads us to the specification

$$
\tilde{s}_{i t} \mid s_{i} \sim N\left(s_{i}, \frac{\sigma_{i}^{2}}{x_{i t}}\right) \text { and so } \frac{x_{i t}}{\sigma_{i}^{2}}=\text { Clarity of Message, }
$$

so that the overall clarity of the message is the product of the leader's clarity of communication and the time spent deciphering what it is that she is trying to convey. A constraint $\sum_{i=1}^{n} x_{i t}=1$ captures the limited attention span of an activist: paying close attention to one leader carries an opportunity cost, since less attention is paid to others.

With this extension in hand, we analyze a game in which activists choose both who to listen to and how to react to the speeches they hear. Specifically, activist $t$ chooses $x_{t} \in \mathbb{R}_{+}^{n}$ satisfying the budget constraint on her time and then, given what she hears, chooses a policy to advocate. Payoffs are as before. 
As previously, while an activist imposes externalities on others via his effect on the party line $\bar{a}$, the positive and negative externalities cancel out. Thus to find the equilibrium we can again treat each activist as maximizing aggregate party welfare. Any strict equilibrium involves the symmetric choice of attention, hence we can drop the subscript $t$ so that each activist devotes a fraction of time $x_{i}$ to leader $i$. Whereas leader $i$ 's clarity of communication is still indexed by $1 / \sigma_{i}^{2}$, the clarity of the message received from her is now $x_{i} / \sigma_{i}^{2}$. Exploiting Proposition 1, party welfare satisfies

$$
\text { Party Welfare }=\bar{u}-\frac{1}{\sum_{i=1}^{n} \hat{\psi}_{i}} \quad \text { where } \quad \hat{\psi}_{i}=\frac{1}{\pi \kappa_{i}^{2}+\left[\sigma_{i}^{2} / x_{i}\right]},
$$

and so the equilibrium values of $x_{i}$ maximize $\sum_{i=1}^{n} \hat{\psi}_{i}$ subject to $\sum_{i=1}^{n} x_{i} \leq 1$. Since welfare is increasing in the attention paid to each leader, activists will certainly exhaust the time they have available. However, it may be that $x_{i}=0$ for some $i$ : activists may ignore some leaders. Evaluating which leaders receive attention and which do not can provide insights into the formation of a natural oligarchy of influential leaders; a necessary condition for a leader to have influence is that activists pay attention to her message. Before performing this evaluation, and for simplicity of exposition, we order (without loss of generality) the leaders in order of decreasing clarity, so that $\sigma_{1}^{2}<\cdots<\sigma_{n}^{2}$.

Proposition 3. When activists choose who to listen to, a strict Bayesian Nash equilibrium exists. It is unique and symmetric. Activists listen only to an elite subset of leaders comprising the $m$ clearest communicators: ordering leaders by decreasing clarity, so that $\sigma_{1}^{2}<\cdots<\sigma_{n}^{2}$, there is some $m \in\{1, \ldots, n\}$ such that $x_{i}>0$ for $i \leq m$ and $x_{i}=0$ for all $i>m$. For $i \leq m$,

$$
x_{i}=\frac{\sigma_{i}\left(K-\sigma_{i}\right)}{\pi \kappa_{i}^{2}} \text { where } K=\frac{\pi+\sum_{j=1}^{m}\left[\sigma_{j}^{2} / \kappa_{j}^{2}\right]}{\sum_{j=1}^{m}\left[\sigma_{j} / \kappa_{j}^{2}\right]} .
$$

Amongst the elite, the attention paid to a leader increases with her sense of direction, but not always with the clarity of her communication: attention paid to her is increasing in her clarity when $\sigma_{i}>K / 2$, but decreasing when $\sigma_{i}<K / 2$. The size $m$ of the elite increases with activists' concern $\pi$ for policy versus party unity, but decreases with each leader's sense of direction.

When all $n$ leaders share the same communication skills, so that $\sigma_{i}=\sigma_{j}$ for all $i \neq j$, then the attention paid to each leader is proportional to her sense of direction. However, when leaders differ in their coherence richer results emerge.

The leaders toward whom activists gravitate (so that $x_{i}>0$ ) are the clearest communicators. Correspondingly, once a leader's clarity of communication falls below a threshold (that is, when $\sigma_{i}>K$ ) activists will ignore her; such a leader can have no influence. Whilst intuitively one might think that a good sense of direction would demand attention, our result highlights the importance of getting the message across. 
Despite this finding, communicating too clearly can deflect attention toward others: when $\sigma_{i}<K / 2$ (the noise in a leader's speech is relatively low) an increase in her clarity reduces the attention paid to her. We return to this issue in due course, when we evalute a leader's incentive to either clarify or obfuscate when speaking to her party.

Nevertheless, sufficient clarity of communication remains a pre-requisite for successful leadership. One possibility emerging from Proposition 3 is that $m=1$, so that activists pay attention only to the leader with the best communication skills, ignoring the speeches made by others. Such a leader, should she exist, enjoys undivided attention, and thus undiluted influence; she becomes a de facto dictator. But when will such a leader emerge?

Proposition 4. Recall that we have (without loss of generality) ordered the leaders by decreasing clarity, so that $\sigma_{1}^{2}<\cdots<\sigma_{n}^{2}$. The clearest communicator is a de facto dictator if and only if

$$
\sigma_{2}^{2} \geq \sigma_{1}^{2} \times\left[1+\frac{\pi \kappa_{1}^{2}}{\sigma_{1}^{2}}\right]^{2} .
$$

The right-hand side of this inequality is convex in $\sigma_{1}^{2}$, is minimized by $\sigma_{1}^{2}=\pi \kappa_{1}^{2}$, and explodes as $\sigma_{1}^{2} \rightarrow 0$. Hence, for a leader to enjoy exclusive attention as a de facto dictator she needs to communicate imperfectly. The clarity which best supports her dictatorship (minimizing the righthand side of the inequality) increases with her sense of direction and the desire for party unity.

A de facto dictator must be the clearest communicator (Proposition 3). For her to enjoy exclusive attention, however, the clarity of her clearest competitor must be sufficiently low; equivalently, $\sigma_{2}^{2}$ (and $\sigma_{i}^{2}$ for other leaders $i>2$ ) must be large. Being the clearest communicator is not enough; $\sigma_{1}^{2}<\sigma_{2}^{2}$ is sufficient for dictatorship in only two cases. The first case is when $\pi \rightarrow 0$, so that activists care only about party unity, and the clearest communicator is best able to provide a focal policy around which the party membership can rally. The second case is when $\kappa_{1}^{2} \rightarrow 0$, so that the best communicator also enjoys an excellent sense of direction; she is a Churchillian leader who trumps all others.

A leader succeeds in monopolizing the agenda when the inequality in Proposition 4 is satisfied; this is easiest when $\sigma_{1}^{2}=\pi \kappa_{1}^{2}>0$. Figure 1 illustrates: with the parameter values shown, when Leader 1 chooses $\sigma_{1}^{2}=0.25$ (or $\sigma_{1}=0.5$ in the figure) and $\sigma_{2}^{2} \geq 1$ then Leader 2 receives no attention and enjoys no influence. However, if Leader 1 speaks more clearly then eventually Leader 2 attracts an audience. The lesson is clear: if a leader wishes to monopolize the agenda, and therefore maintain complete influence, then she needs to avoid perfect clarity; better communication can sometimes divert attention toward others. Moreover, the clarity $1 /\left(\pi \kappa_{1}^{2}\right)$ that maximizes the range of de facto dictatorship increases with a leader's sense of direction; if she is to maintain exclusive attention then a leader can get away with speaking more clearly only when she has more to say. 


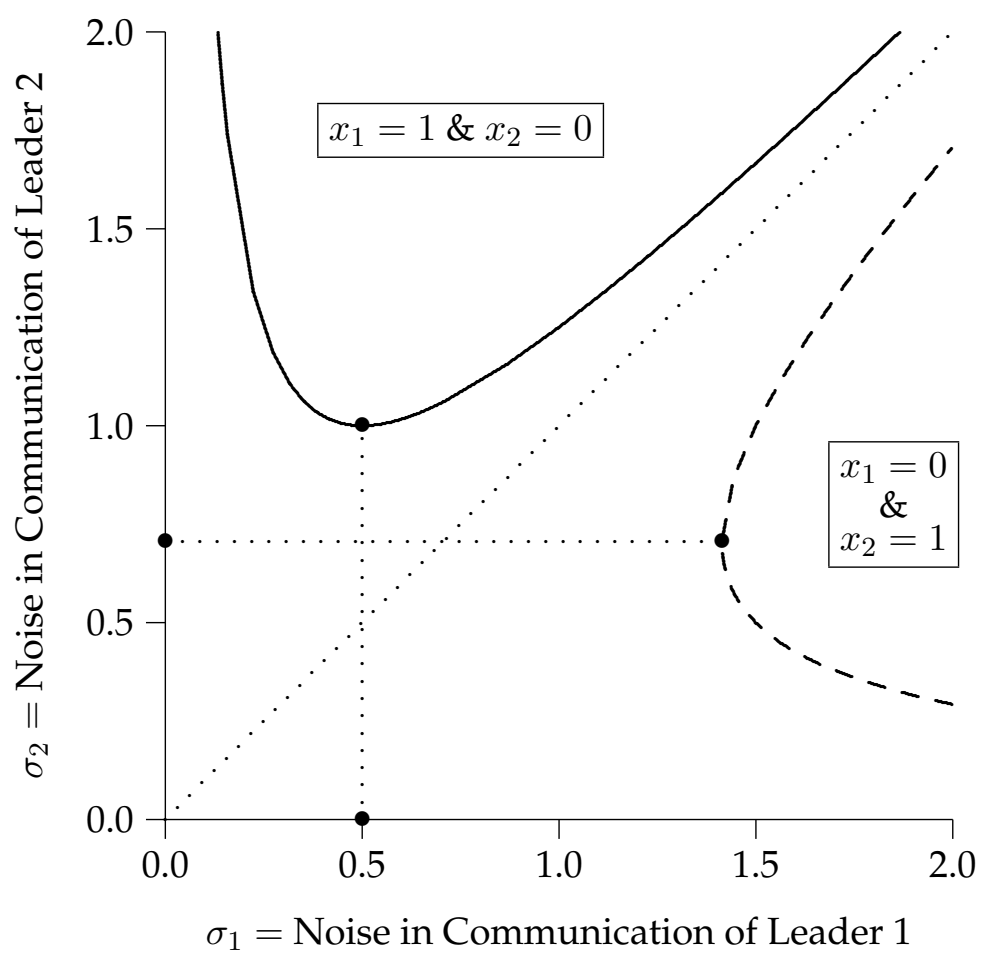

This figure uses the parameter choices: $\pi=\frac{1}{2}, \kappa_{1}^{2}=\frac{1}{2}$ and $\kappa_{2}^{2}=1$. Leader 1 enjoys unreserved attention whenever $\sigma_{2}$ lies above the solid line; simililarly, leader 2 enjoys unreserved attention whenever $\sigma_{1}$ lies to the right of the broken line. The bullets indicate the values $\sigma_{i}^{2}=\pi \kappa_{i}^{2}$ for $i \in\{1,2\}$ that leader $i$ would choose if she wanted to make it as difficult as possible for leader $j \neq i$ to receive any attention.

FIGURE 1. Paying Attention To A Single Leader

Propositions 3 and 4 suggest that a leader can sometimes attract attention by speaking less clearly; in fact, some obfuscation is necessary if a leader is to maintain complete influence as a de facto dictator. To understand why this is so recall that an activist gathers information to develop an understanding of his environment. Listening to leaders helps him to do this, but given time contraints he will not listen to a leader longer than he needs to. When a leader is a good communicator, an activist can discern her position in a short period of time; with time to spare, he moves on to gather more information.

It is also worthwhile noting that the focus of activists' attention depends upon their relative preference for policy versus party unity. From Proposition 3, the size $m$ of the elite to whom activists listen declines with the policy-concern parameter $\pi$. Hence, as the desire for party unity grows (so that $\pi$ falls) the size of the leadership elite shrinks. Indeed, inspection of Proposition 4 reveals that the best communicator will become a de facto dictator when $\pi$ is small enough. The intuition is natural: when activists care only about unity then the information regarding policy provided by leaders is irrelevant, and all that matters is to find a clear focal point around which the membership can coalesce. 


\section{ATTENTION-SEEKING LEADERS}

We have shown that the quality of information received by activists depends endogenously on the willingness of her audience to listen. Taking a further step in our analysis, we now allow a leader's clarity of communication to be chosen endogenously. We assume that leaders crave attention: a leader selects the clarity which maximizes the attention paid to her; simply, leaders like a large and attentive audience. Formally, we study a simultaneous-move game in which each leader $i$ chooses the variance $\sigma_{i}^{2}$ of the noise in her speech; equivalently, her clarity of communication is the precision $1 / \sigma_{i}^{2}$. Her payoff is the attention $x_{i}$ emerging endogenously from the choices of activists (Proposition 3).

An attention-seeking leader must convey some information and cannot simply babble; if the noise in her speech is too large (from Proposition 3, this is so when $\sigma_{i}>K$ ) she will be ignored. But she does not wish to speak with perfect clarity. When $\sigma_{i}<K / 2$, the attention paid to her increases with noise added to her speech, and so optimally she obfuscates.

Proposition 5. When an attention-seeking leader is free to choose any level of clarity (so that she could speak with perfect clarity if she desired) then she obfuscates by setting $\sigma_{i}^{2}>0$. Fixing the clarity of others, her optimally chosen clarity increases with each leader's sense of direction and activists' desire for party unity. When leaders simultaneously choose their levels of clarity there is a unique Nash equilibrium in which all leaders choose

$$
\text { Clarity of Communication }=\frac{1}{\sigma^{2}}=\frac{1}{\pi} \sum_{i=1}^{n} \frac{1}{\kappa_{i}^{2}} \text {, }
$$

which increases with each leader's sense of direction and activists' desire for party unity.

Further insight emerges from a convenient analogy. In our model, each activist is a consumer of costly information. He allocates time $x_{i}$, rather than money, to $n$ competing information products (in the form of leadership speeches). His purchase from leader $i$ is the clarity $x_{i} / \sigma_{i}^{2}$ of her message. Now when an attention-seeking leader chooses clarity to maximize attention paid to her, she acts as would a revenue maximizing oligopolist. Adding noise to her communication is equivalent to a price hike: it directly increases her revenue (in the form of the attention paid to her) for a given quantity (clarity of message); on the other hand, obfuscation prompts an activist to lower his demand for her product (speech) by substituting to others. Balancing the two effects of a change in clarity generates an intermediate solution. Perhaps surprisingly, the unique Nash equilibrium identified by Proposition 5 (illustrated in Figure 2) reveals that all leaders speak with the same clarity, even thought they do not share a common sense of direction. 


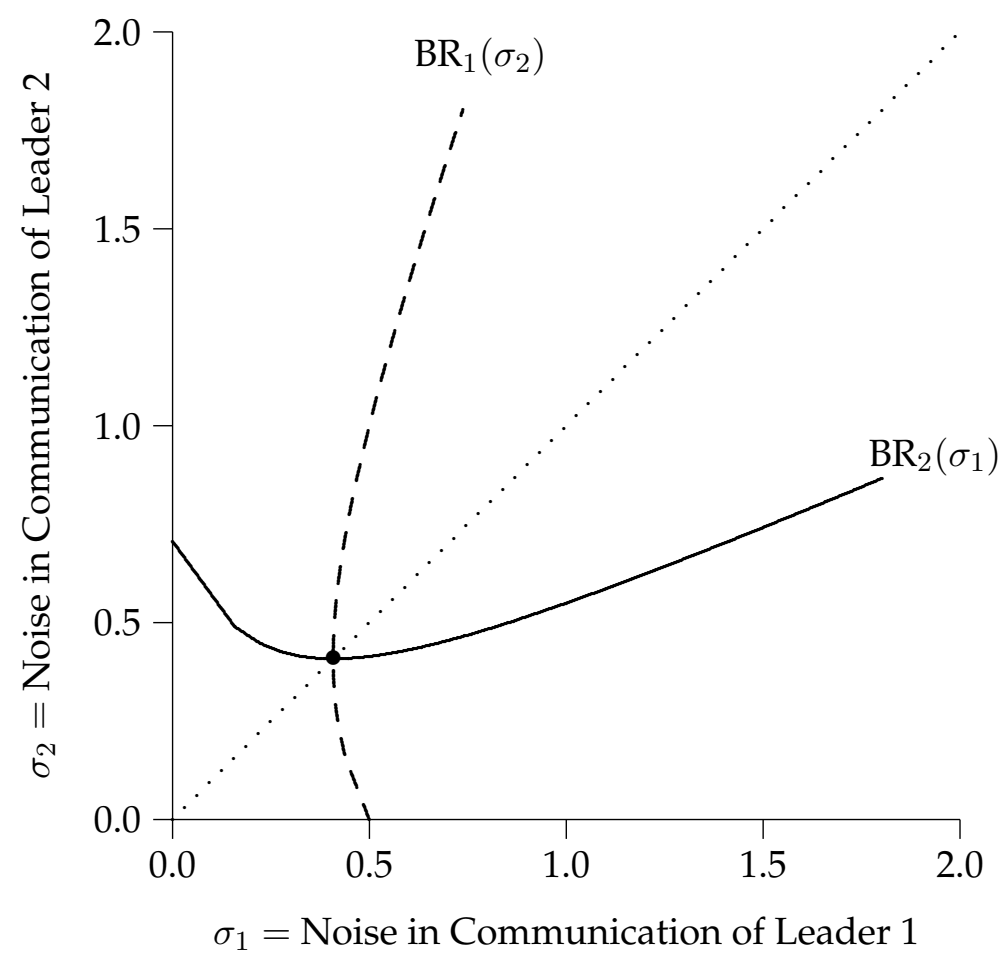

This figure uses the parameter choices: $\pi=\frac{1}{2}, \kappa_{1}^{2}=\frac{1}{2}$ and $\kappa_{2}^{2}=1$. It illustrates the two reaction (or best reply) functions for two attention-seeking leaders. The unique intersection corresponds to the unique Nash equilibrium; it lies on the 45-degree line and hence leaders speak with equal clarity in equilibrium.

FIGURE 2. Endogenous Leadership Clarity

To understand why, consider the solution for $x_{i}$ from Proposition 3. The attention (relative to others) paid to each leader increases proportionally with her sense of direction. However, the way in which attention reacts to clarity is the same for each leader via the term $\sigma_{i}\left(K-\sigma_{i}\right)$. Returning to our analogy, local to the equilibrium the demand curves (for clarity of message) faced by different leaders are the same shape; however, those with a better sense of direction benefit from proportionally higher demand for any given price. Since $1 / \kappa_{i}^{2}$ simply scales the demand curve along a quantity axis, the revenue-maximizing price is independent of it. This leads naturally to a symmetric equilibrium (Figure 2).

Proposition 5 also predicts that the (common) clarity of leaders' communication increases with every leader's sense of direction. An increase in a leader's sense of direction enhances demand for her information as activists divert attention away from others. This has a knock-on effect since it forces other leaders to compete harder, by increasing the clarity of their communication. This feeds back, in turn, to the original leader. One aspect of this effect seems natural: a leader speaks more clearly when she has more to say. More subtly, however, a leader speaks more clearly when others have more to say. 
Finally, Proposition 5 predicts that leaders' rhetoric reacts to the relative preferences of the party membership. As activists emphasize party unity relative to choosing the policy closest to $\theta$, that is as $\pi$ falls, leaders speak with increasing clarity. Coordination requires precise communication and leaders respond by speaking more clearly.

We observe the full importance of this point when we consider the welfare implications of attention-seeking leaders. Recall (Proposition 1) that party welfare increases with $\sum_{i=1}^{n} \hat{\psi}_{i}$, and so the index $\hat{\psi}_{i}$ measures both good leadership and successful leadership; it reacts positively to a leader's clarity as well as her sense of direction. Allowing the attention paid to leaders (and hence the overall clarity of their messages) to be determined endogenously, the situation becomes more complex. Clarity of communication remains critical in ensuring that a leader receives some attention and, therefore, enjoys influence. However, whereas increased clarity benefits activists and is thus a component of good leadership, an attempt to seek attention or to monopolize the agenda may induce a leader to reduce her clarity; a successful leader (as opposed to a good leader) may obfuscate. The vanity of attention seekers separates good and successful leadership.

Allowing our leaders to play a game in which they simultaneously choose their rhetorical strategies might be expected to complicate things further. In practice it simplifies matters. Since all leaders choose the same clarity, the attention paid to each leader is proportional to her sense of direction. The leadership index reduces to

$$
\hat{\psi}_{i}=\frac{1}{\pi \kappa_{i}^{2}+\left[\sigma_{i}^{2} / x_{i}\right]}=\frac{1}{2 \pi \kappa_{i}^{2}} .
$$

By inspection, the key determinant of a leader's success becomes her sense of direction.

Proposition 6. When leaders choose their clarity and activists choose who to listen to, the equilibrium influence of a leader is proportional to her sense of direction. Furthermore,

$$
\text { Party Welfare }=\bar{u}-\frac{2 \pi}{\sum_{i=1}^{n}\left[1 / \kappa_{i}^{2}\right]},
$$

which increases with the leaders' combined sense of direction and the desire for party unity. Furthermore the variance $\mathrm{E}\left[\left(a_{t}-\theta\right)^{2} \mid \theta\right]$ of activists' actions around the ideal policy grows with $\pi$, and so a greater desire for party unity improves the policy performance of the party.

Party welfare falls as $\pi$ (activists' relative concern for policy) grows. This need not be surprising, since the policy component of an activist's loss function reacts to two sources of noise rather than one. More surprising, however, is the fact that the variance of activists' actions around the ideal policy falls as $\pi$ shrinks. Recall that $\pi$ indexes the extent to which activists care about choosing the ideal policy. Thus, paradoxically, activists become better at advocating the best policy as they care less about doing so. 
Recognizing the endogenous quality of leadership corrects the intuition. When activists desire unity, leaders respond by speaking clearly. In so doing they generate common expectations about the party line. When such a common understanding emerges, the party acts more cohesively. But this is not the only effect since, when leaders speak more clearly, activists are able also to understand better their political environment. Moving away from a desire to back good policies generates a need for coherent unifying leadership; this reduces the obfuscation of attention-seekers and so improves policy performance.

\section{CONCLUDING REMARKS}

Leadership is a central ingredient of good government. Leaders can help individuals to learn about their environment and to develop a common understanding of how others will behave. As argued by Levi (2006,p. 10) "leadership_-both of government and within civil society-provides the agency that coordinates the efforts of others." We have explored a scenario in which leadership provides just such an agency. In our model a mass of party activists wish to (i) advocate the best policy and (ii) unify behind a common party line. To learn about their environment and to form expectations about the likely actions taken by fellow partisans, they listen to the speeches made by party leaders. These leaders are distinguished by their ability to make policy judgements (sense of direction) and their ability to express their views (clarity of communication).

In analyzing the policy advocacy of activists we were able to assess how a leader's influence is affected by her skill set. Treating a leader's skills set as exogenous, we found that clarity of communication is relatively more important than sense of direction. Of course, an activist can choose to listen to a leader all of the time, some of the time, or not at all. We found that a necessary condition for a leader to receive any attention is that she belongs to the party's clearest communicators; if she is to monopolize the agenda then she must be the most coherent communicator. Interestingly, when activists apportion their time amongst the best communicators (so that no single leader dominates proceedings) they sometimes pay more attention to those with (relatively) inferior communicative ability. Correspondingly, we found when that, when attention-seeking leaders choose their clarity, they obfuscate in order to retain their audience. However, in equilibrium all members of the leadership elite choose the same levels of clarity. Thus, and in contrast to our earlier result, a leader's influence is solely determined by her sense of direction.

Whilst few would deny that leadership plays an important role in influencing people's actions-indeed there is experimental evidence (Humphreys, Masters, and Sandbu, 2006; Güth, Levati, Sutter, and van der Heijden, 2004) that this is the case-to our knowledge there has been no recent formal work which evaluates the influence of different leaders 
according to the skills they possess. Our paper attempts to fill this gap. Of course, there are many leadership qualities we have not considered, but we hope that we have provided a simple basis for further analysis in this area.

We have also tackled the thorny issue of whether leaders can be both good and successful in a model which brings together the information aggregation properties of leadership and the political ambitions of leaders. In our framework, a good leader helps activists understand their environment and coordinate with each other, whilst a successful leader maximizes the attention paid to her. When leaders' skills are exogenous, good leadership and successful leadership are indistinguishable. But when activists choose the amount of attention they give to each leader (and leaders react by choosing the clarity of their communication) a leader's desire for attention, a key component of her political ambitions, drives a wedge between good and successful leadership: A leader increases her success by obfuscating her message; activists receive less information; and consequentially activists are less informed about their environment.

These welfare effects, due to the attention-seeking concerns of leaders, depend critically upon the weighting activists placed on their twin goals. Perhaps surprisingly, there is less obfuscation when activists place more emphasis on following the party line rather than pursuing the best policy. Our message is that when a party emphasizes unity, it provides leaders with the necessary incentives so that good and successful leadership coincide.

This key result is related to our assumption that leaders are attention-seekers. One justification for this focus is that the attention given to a leader is a component of her overall influence; a leader who cares about her influence would do well to maximize the attention paid to her views. Indeed in some cases (as for example when a leader receives undivided attention) attention-seeking and influence-maximizing coincide. Moreover, in most cases the behaviors associated with these motives are similar. ${ }^{9}$ Whilst our results are robust to different motivational assumptions they also incorporate straightforward extensions of the model. For example, our results hold when we consider activists who have access to information sources other than leadership. In sum we hope that our model provides a small step in response to Levi's (2006, p. 11) claim that "still lacking is a model of the origins and means of ensuring good leadership."

\footnotetext{
${ }^{9}$ An influence-seeking leader would ideally wish to monopolize the agenda. Proposition 4 reveals that she must be the best communicator; but if her clarity is too great then activists also follow others. Hence, some obfuscation is necessary if a leader is to dictate. However, when clarity is chosen simultaneously by all leaders then we would expect to see greater clarity than in a pure attention-seeking game. To see this, begin with the equilibrium described in Proposition 5. A marginal increase in clarity has no effect on the attention paid to a leader. However, it does increase the weight placed on her speech and so increases her influence. Thus we expect to see more obfuscation when leaders seek attention rather than influence.
} 


\section{OMitTED PROOFS}

Proof of Proposition 1. Footnote 6 explains the symmetry and play of strict best replies. An advocacy strategy $A\left(\tilde{s}_{t}\right): \mathbb{R}^{n} \mapsto \mathbb{R}$ might be non-linear. However, replication of the procedure used by Morris and Shin (2002) ensures that any equilibrium must involve linear strategies. A formal proof could now proceed by "matching coefficients" (Morris and Shin, 2002). However, we instead build upon the argument presented in the text: the equilibrium must be efficient, since the externalities imposed by an activist must, at the margin, sum to zero. Given the party-welfare measure described in the text, finding the (unique) equilibrium boils down to solving the constrained optimization problem:

$$
\max _{w \in \mathbb{R}_{+}^{n}} \bar{u}-\sum_{i=1}^{n} w_{i}^{2}\left[\pi \kappa_{i}^{2}+\sigma_{i}^{2}\right] \quad \text { subject to } \quad \sum_{i=1}^{m} w_{i} \leq 1 .
$$

This is a well behaved problem and the Kuhn-Tucker conditions are necessary and sufficient for its solution. Introducing the Lagrange multiplier $\lambda$ the first-order conditions take the form $2 w_{i}\left[\pi \kappa_{i}^{2}+\sigma_{i}^{2}\right]=\lambda$ for each $i$, or equivalently $w_{i}=\lambda \hat{\psi}_{i} / 2$, amd their joint solution is given in the statement of the proposition. The welfare measure follows by substitution, and the comparative-static claims follow by inspection.

Proof of Proposition 2. The expression for $\hat{\psi}_{i}$ follows from simple algebra, and the comparative static claims regarding $\psi_{i}$ and $\rho_{i}$ follow by inspection. Taking logarithms and differentiating with respect to $\pi$ we obtain

$$
\begin{aligned}
\frac{\partial \log \left(\hat{\psi}_{i} / \hat{\psi}_{j}\right)}{\partial \pi} & =\left[\frac{-\rho_{i} \psi_{i}}{\left(\left(1-\rho_{i}\right)+\pi \rho_{i}\right)^{2}} \times \frac{\left(1-\rho_{i}\right)+\pi \rho_{i}}{\psi_{i}}\right]-\left[\frac{-\rho_{j} \psi_{j}}{\left(\left(1-\rho_{j}\right)+\pi \rho_{j}\right)^{2}} \times \frac{\left(1-\rho_{j}\right)+\pi \rho_{j}}{\psi_{j}}\right] \\
& =\frac{\rho_{j}}{\left(1-\rho_{j}\right)+\pi \rho_{j}}-\frac{\rho_{i}}{\left(1-\rho_{i}\right)+\pi \rho_{i}}<0 \Leftrightarrow \rho_{i}>\rho_{j},
\end{aligned}
$$

which yields the final claim of the proposition.

Proof of Proposition 3. A strict Bayesian Nash equilibrium entails the play of a unique strict best reply by each player-type, and this best reply is independent of the player's label, since each player is negligible. Hence any strict equilbrium must be symmetric. Any externalities arising from a player's behavior feed via the party line $\bar{a}$. As argued in the text, positive and negative externalities cancel yielding a zero net effect at the margin. Hence, the equilibrium maximizes party welfare. Now,

$$
\text { Party Welfare }=\bar{u}-\frac{1}{\sum_{i=1}^{n} \hat{\psi}_{i}} \quad \text { where } \quad \hat{\psi}_{i}=\frac{1}{\pi \kappa_{i}^{2}+\left[\sigma_{i}^{2} / x_{i}\right]},
$$


and so the equilibrium attention levels must solve

$$
\max _{x \in \mathbb{R}_{+}^{n}} \sum_{i=1}^{n} \frac{1}{\pi \kappa_{i}^{2}+\left[\sigma_{i}^{2} / x_{i}\right]} \quad \text { subject to } \quad \sum_{i=1}^{n} x_{i} \leq 1 .
$$

The constraint function is convex. The objective is strictly concave, since its $i$ th component is concave in $x_{i}$. To see this, differentiate $\hat{\psi}_{i}$ with respect to $x_{i}$, to obtain

$$
\frac{\partial \hat{\psi}_{i}}{\partial x_{i}}=\frac{\sigma_{i}^{2}}{\left(\pi \kappa_{i}^{2}+\left[\sigma_{i}^{2} / x_{i}\right]\right)^{2} x_{i}^{2}}=\frac{\sigma_{i}^{2}}{\left(\pi x_{i} \kappa_{i}^{2}+\sigma_{i}^{2}\right)^{2}},
$$

which is positive and strictly decreasing in $x_{i}$. Since the objective function is strictly concave, there is a unique solution and hence a unique equilibrium. The usual Kuhn-Tucker conditions are both necessary and sufficient. Introducing the Lagrange multiplier $\lambda>0$ for the attention-span constraint (the constraint binds since welfare is strictly increasing in attention and so the multiplier is strictly positive) for $x_{i}>0$, the first-order condition is

$$
\frac{\partial \hat{\psi}_{i}}{\partial x_{i}}=\frac{\sigma_{i}^{2}}{\left(\pi x_{i} \kappa_{i}^{2}+\sigma_{i}^{2}\right)^{2}}=\lambda \quad \Rightarrow \quad \lambda<\frac{1}{\sigma_{i}^{2}} .
$$

Hence any leader who attracts attention must speak with clarity exceeding $\lambda$. It follows that if a leader is ignored, (that is $x_{i}=0$ ), then it must be the case that

$$
\left.\frac{\partial \hat{\psi}_{i}}{\partial x_{i}}\right|_{x_{i}=0}=\frac{1}{\sigma_{i}^{2}} \leq \lambda
$$

and so the clarity of communication of such a leader falls below $\lambda$. Taken together, this means that the leaders who attract attention must be the best communicators: $x_{i}>0$ if and only if $i \leq m$ for some $m \in\{1, \ldots, n\}$. For this elite of $m$ leaders,

$$
\frac{\sigma_{i}^{2}}{\left(\pi x_{i} \kappa_{i}^{2}+\sigma_{i}^{2}\right)^{2}}=\lambda \quad \Leftrightarrow \quad x_{i}=\frac{\sigma_{i}\left(1-\sigma_{i} \sqrt{\lambda}\right)}{\pi \kappa_{i}^{2} \sqrt{\lambda}}=\frac{\sigma_{i}\left(K-\sigma_{i}\right)}{\pi \kappa_{i}^{2}} \quad \text { where } \quad K \equiv \frac{1}{\sqrt{\lambda}} .
$$

To find the value of $K$ (and hence the value $\lambda=1 / K^{2}$ of the Lagrange multiplier) we sum over the $m$-strong elite and set $\sum_{i=1}^{m} x_{i}=1$. Hence

$$
1=\sum_{i=1}^{m} \frac{\sigma_{i}\left(K-\sigma_{i}\right)}{\pi \kappa_{i}^{2}} \Leftrightarrow \pi+\sum_{i=1}^{m} \frac{\sigma_{i}^{2}}{\kappa_{i}^{2}}=K \sum_{i=1}^{m} \frac{\sigma_{i}}{\kappa_{i}^{2}},
$$

which solves for $K$ given in the proposition. We need only check that the sense of direction of any leader $i>m$ falls below $\lambda$, or equivalently $\sigma_{i} \geq K$. If so, and so long as $\sigma_{i}<K$ for all $i \leq m$, then we have a solution. If $\sigma_{m+1}<K$ then we expand the elite to size $m+1$. We continue doing this until we find the equilibrium elite size $m$. Finally, we turn to the 
comparative-static claims. Differentiate $x_{i}$ with respect to $\sigma_{i}$ to obtain:

$$
\frac{\partial x_{i}}{\partial \sigma_{i}}=\frac{1}{\pi \kappa_{i}^{2}}\left[K-2 \sigma_{i}+\sigma_{i} \frac{\partial K}{\partial \sigma_{i}}\right] .
$$

Taking $K$ from the proposition and differentiating with respect to $\sigma_{i}$ we obtain

$$
\frac{\partial K}{\partial \sigma_{i}}=\frac{\left(2 \sigma_{i} / \kappa_{i}^{2}\right)\left(\sum_{j=1}^{m}\left[\sigma_{j} / \kappa_{j}^{2}\right]\right)-\left(1 / \kappa_{i}^{2}\right)\left(\pi+\sum_{j=1}^{m}\left[\sigma_{j}^{2} / \kappa_{j}^{2}\right]\right)}{\left(\sum_{j=1}^{m}\left[\sigma_{j} / \kappa_{j}^{2}\right]\right)^{2}}=\frac{2 \sigma_{i}-K}{\kappa_{i}^{2} \sum_{j=1}^{m}\left[\sigma_{j} / \kappa_{j}^{2}\right]},
$$

which upon substitution back into $\partial x_{i} / \partial \sigma_{i}$ yields:

$$
\frac{\partial x_{i}}{\partial \sigma_{i}}=\frac{K-2 \sigma_{i}}{\pi \kappa_{i}^{2}}\left[1-\frac{\sigma_{i}}{\kappa_{i}^{2} \sum_{j=1}^{m}\left[\sigma_{j} / \kappa_{j}^{2}\right]}\right]>0 \quad \Leftrightarrow \quad \sigma_{i}<\frac{K}{2},
$$

since the bracketed term is strictly positive. For the final claim, notice that (other things equal) $K$ is increasing in $\pi$. An increase in $\pi$ makes it harder to satisfy $\sigma_{i}>K$, and so $m$ must increase with $\pi$.

Proof of Proposition 4. For attention to be focused on a elite of size $m$, the clarity of $i>m$ must satisfy $\sigma_{i}^{2} \geq K^{2}$ where $K$ is from Proposition 3. For the special case of $m=1$,

$$
K=\frac{\pi+\left[\sigma_{1}^{2} / \kappa_{1}^{2}\right]}{\sigma_{1} / \kappa_{1}^{2}}=\sigma_{1}\left[1+\frac{\pi \kappa_{1}^{2}}{\sigma_{1}^{2}}\right] .
$$

Squaring yields the lower bound on $\sigma_{2}^{2}$ given in the proposition. Now,

$$
\frac{\partial K^{2}}{\partial \sigma_{1}^{2}}=\left[1+\frac{\pi \kappa_{1}^{2}}{\sigma_{1}^{2}}\right]^{2}-2 \sigma_{1}^{2}\left[1+\frac{\pi \kappa_{1}^{2}}{\sigma_{1}^{2}}\right] \frac{\pi \kappa_{1}^{2}}{\sigma_{1}^{4}}=1-\left[\frac{\pi \kappa_{1}^{2}}{\sigma_{1}^{2}}\right]^{2} .
$$

This is increasing in $\sigma_{1}^{2}$ and hence $K^{2}$ is convex in $\sigma_{1}^{2}$. Setting the derivative to zero yields $\sigma_{1}^{2}=\pi \kappa_{1}^{2}$, as claimed. The remaining claims follow by inspection.

Proof of Proposition 5. $x_{i}$ is increasing in $\sigma_{i}$ for $\sigma_{i}<K / 2$ and decreasing for $\sigma_{i}>K / 2$ and so is maximized if and only if $\sigma_{i}=K / 2$. To find the effect of a parameter on a best reply we find its effect on $K$ : if a parameter increases $K$ then leader $i$ responds by raising $\sigma_{i}$ until $\sigma_{i}=K / 2$ once more, reducing her clarity. We observe that $K$ increases with $\pi$, and so clarity increases with the desire for party unity. Differentiating $K$ with respect to $1 / \kappa_{i}^{2}$,

$$
\frac{\partial K}{\partial\left[1 / \kappa_{i}^{2}\right]}=\frac{\sigma_{i}^{2}\left(\sum_{j=1}^{m}\left[\sigma_{j} / \kappa_{j}^{2}\right]\right)-\sigma_{i}\left(\pi+\sum_{j=1}^{m}\left[\sigma_{j}^{2} / \kappa_{j}^{2}\right]\right)}{\left(\sum_{j=1}^{m}\left[\sigma_{j} / \kappa_{j}^{2}\right]\right)^{2}}=\frac{\sigma_{i}^{2}-\sigma_{i} K}{\sum_{j=1}^{m}\left[\sigma_{j} / \kappa_{j}^{2}\right]},
$$

which is positive if and only if $\sigma_{i}>K$. Of course, if $\sigma_{i}>K$ then $x_{i}=0$ and leader $i$ is not entered in the formula for $K$. Thus, if leader $i$ attracts any attention, so that $\sigma_{i}<K$, then $K$ is decreasing in her sense of direction. To find the equilibrium of the attention-seeking 
game we set $\sigma_{i}=\sigma=K / 2$ for all $i$. Substituting $K=2 \sigma$ into the definition of $K$,

$$
2 \sigma=\frac{\pi+\sigma^{2} \sum_{j=1}^{m}\left[1 / \kappa_{j}^{2}\right]}{\sigma \sum_{j=1}^{m}\left[1 / \kappa_{j}^{2}\right]} \Leftrightarrow 2 \sigma^{2}=\frac{\pi}{\sum_{j=1}^{m}\left[1 / \kappa_{j}^{2}\right]}+\sigma^{2},
$$

yielding the solution from the proposition. The final claim follows by inspection.

Proof of Proposition 6. Party welfare is $\bar{u}-1 / \sum_{i=1}^{n} \hat{\psi}_{i}$. Substituting in the expression for $\hat{\psi}_{i}$ given in the text (obtained by simple algebra) yields the welfare stated in the proposition. The comparative-static claims follow straightforwardly. Regarding policy performance,

$$
\mathrm{E}\left[\left(a_{t}-\theta\right)^{2} \mid \theta\right]=\sum_{i=1}^{n} w_{i}^{2}\left(\kappa_{i}^{2}+\frac{\sigma_{i}^{2}}{x_{i}}\right)=\frac{1+\pi}{\sum_{i=1}^{n} 1 / \kappa_{i}^{2}},
$$

where the equality follows from substitution and simplification. This increases with $\pi$ and decreases with the aggregate sense of direction of the leaders.

Construction of Figure 1. Uses the formula from Proposition 4.

Construction of Figure 2. To construct this figure we computed the reaction function for a leader $i$. Note that a leader $i$ chooses her clarity of optimally when $\sigma_{i}=K / 2$. Hence

$$
2 \sigma_{i}=K=\frac{\pi+\sum_{j=1}^{m}\left[\sigma_{j}^{2} / \kappa_{j}^{2}\right]}{\sum_{j=1}^{m}\left[\sigma_{j} / \kappa_{j}^{2}\right]}=\frac{\pi \kappa_{i}^{2}+A+\sigma_{i}^{2}}{B+\sigma_{i}} \Leftrightarrow \sigma_{i}^{2}+B \sigma_{i}-\left(A+\pi \kappa_{i}^{2}\right)=0,
$$

where $A \equiv \kappa_{i}^{2} \sum_{j \neq i}\left[\sigma_{j}^{2} / \kappa_{j}^{2}\right]$ and $B \equiv \kappa_{i}^{2} \sum_{j \neq i}\left[\sigma_{j} / \kappa_{j}^{2}\right]$. Solving for the positive root,

$$
\sigma_{i}=-B+\sqrt{A+B^{2}+\pi \kappa_{i}^{2}}=\sqrt{\pi \kappa_{i}^{2}+\kappa_{i}^{2} \sum_{j \neq i} \frac{\sigma_{j}^{2}}{\kappa_{j}^{2}}+\kappa_{i}^{4}\left[\sum_{j \neq i} \frac{\sigma_{j}}{\kappa_{j}^{2}}\right]^{2}}-\kappa_{i}^{2} \sum_{j \neq i} \frac{\sigma_{j}}{\kappa_{j}^{2}} .
$$

For the case of two players these reduces to

$$
\sigma_{i}=\sqrt{\pi \kappa_{i}^{2}+\sigma_{j}^{2}\left[\frac{\kappa_{i}^{2}}{\kappa_{j}^{2}}+\frac{\kappa_{i}^{4}}{\kappa_{j}^{4}}\right]}-\sigma_{j} \frac{\kappa_{i}^{2}}{\kappa_{j}^{2}},
$$

which is the formula used in the construction of Figure 2. 


\section{REFERENCES}

Angeletos, G.-M., C. Hellwig, And A. Pavan (2006): “Dynamic Global Games of Regime Change: Learning, Multiplicity, and Timing of Attacks," Econometrica, forthcoming.

Angeletos, G.-M., AND A. PAVAN (2004): “Transparency of Information and Coordination in Economies with Investment Complementarities," American Economic Review: AEA Papers and Proceedings, 94(2), 91-8. (2006): “Efficient Use of Information and Social Value of Information," Econometrica, forthcoming.

Aragonés, E., AND Z. NeEMAN (2000): “Strategic Ambiguity in Electoral Competition," Journal of Theoretical Politics, 12(2), 183-204.

BRAND, H. W. (2005): Andrew Jackson: His Life and Times. Doubleday.

Bueno de Mesquita, B., J. D. Morrow, R. M. Siverson, And A. Smith (2002): "Political Institutions, Policy Choice, and the Survival of Leaders," British Journal of Political Science, 32(4), 559-90.

Bueno de Mesquita, B., A. Smith, R. M. Siverson, And J. D. Morrow (2003): The Logic of Political Survival. MIT Press, Cambridge, MA.

CAlvert, R. L. (1995): “The Rational Choice of Social Institutions: Cooperation, Coordination, and Communication," in Modern Political Economy: Old Topics, New Directions, ed. by J. S. Banks, and E. A. Hanushek. Cambridge University Press, Cambridge, UK.

CARWARdine, R. J. (2003): Lincoln. Pearson Longman, Harlow.

CRAWFORD, V. P., AND J. SOBEL (1982): “Strategic Information Transmission," Econometrica, 50(6), 1431-51.

Dewan, T., AND D. P. MyatT (2006): “Leading the Party: Coordination, Direction amd Communication," Annual Meetings of the American Political Science Association.

EDMOND, C. (2005): “Information Manipulation, Coordination, and Regime Change," Working Paper.

ELLIS, J. J. (2005): His Excellency: George Washington. Faber, London.

FIORINA, M. P., AND K. A. SHePSle (1989): “Formal Theories of Leadership: Agents, AgendaSetters, and Entrepreneurs," in Leadership and Politics: New Perspectives in Political Science, ed. by B. D. Jones, pp. 17-41. University Press Kansas, Lawrence.

Gilligan, T. W., AND K. KRehbiel (1987): “Collective Decisionmaking and Standing Committees: An Informational Rationale for Restrictive Ammendment Procedures," Journal of Law, Economics, and Organization, 3(2), 287-335.

GÜth, W., M. V. Levati, M. Sutter, And E. VAn Der Heijden (2004): “Leadership and Cooperation in Public Goods Experiments," Max Planck Institute of Economics.

Hermalin, B. E. (1998): “Toward an Economic Theory of Leadership: Leading by Example," American Economic Review, 88(5), 1188-206.

Holmströм, B. (1982): “Moral Hazard in Teams," Bell Journal of Economics, 13(2), 324-40. 
Humphreys, M., W. Masters, And M. E. SAndbu (2006): “The Role of Leadership in Democratic Deliberations: Results from a Field Experiment in São Tomé and Principe," World Politics, forthcoming.

Kroszner, R. S., AND T. Stratmann (2005): “Corporate Campaign Contributions, Repeat Giving and the Rewards to Legislator Reputation," Journal of Law and Economics, 48(2), 41-71.

Levi, M. (2006): "Why We Need a New Theory of Government," Perspectives on Politics, 4(1), 5-19.

LI, H., S. Rosen, AND W. Suen (2001): "Conflicts and Common Interests in Committees," American Economic Review, 91(3), 1478-97.

Mierowitz, A. (2005): "Informational Party Primaries and Strategic Ambiguity," Journal of Theoretical Politics, 17(1), 107-36.

MORRIS, S., AND H. S. SHIN (2002): "Social Value of Public Information," American Economic Review, 92(5), 1521-34.

Myerson, R. B. (2004): “Justice, Institutions, and Multiple Equilibria," Chicago Journal of International Law, 5(1), 91-107.

PAge, B. I. (1996): “The Theory of Political Ambiguity," American Political Science Review, 70(3), 742-52.

Persico, N. (2004): “Committee Design with Endogenous Information," Review of Economic Studies, 71, 165-91.

RIKER, W. (1996): The Strategy of Rhetoric: Campaigning for the American Constitution. Yale University Press, New Haven.

SHEPSLE, K. A. (1970): “A Note On Zeckhauser's 'Majority Rule with Lotteries on Alternatives'," Quarterly Journal of Economics, 84(2), 705-10.

(1972a): "Parties, Voters and the Risk Environment: A Mathematical Treatment of Electoral Competition under Uncertainty," in Probability Models of Collective Decisison-Making, ed. by R. G. Niemi, and H. F. Weisberg, pp. 273-97. Charles E. Merrill, Columbus, Ohio.

(1972b): “The Strategy of Ambiguity: Uncertainty and Electoral Competition," American Political Science Review, 66(2), 555-69.

Sigelman, L., AND E. H. Buell, JR. (2004): “Avoidance or Engagement? Issue Convergence in US Presidential Campaigns, 1960-2000," American Journal of Political Science, 48(4), 650-61.

ZECKHAUSER, R. (1969): "Majority Rule with Lotteries on Alternatives," Quarterly Journal of Economics, 83(2), 696-703. 